Boletín de la Sociedad Geológica Mexicana

Volumen Conmemorativo del Centenario

Grandes Fronteras Tectónicas de México

Tomo LVII, NÚM. 1, 2005, P. 111-122

\title{
La falla Chacalapa en el sur de Oaxaca
}

\author{
Gustavo Tolson \\ Departamento de Geología Regional, Instituto de Geología, Universidad Nacional Autónoma de México, \\ Ciudad Universitaria, Deleg. Coyoacán, México, D. F., 04510, México \\ tolson@servidor.unam.mx
}

\section{Resumen}

A lo largo de la costa de Oaxaca, entre Puerto Ángel y Santiago Astata, afloran rocas metamórficas del Complejo Xolapa intrusionadas por rocas ígneas de edad Paleógeno a Mioceno sin metamorfismo regional. Ambas unidades se encuentran en contacto tectónico a lo largo de zonas de cizalla con rocas proterozoicas del Complejo Oaxaqueño al norte de Pochutla y con rocas sedimentarias mesozoicas discordantes que sobreyacen los gneises. La principal de estas zonas de cizalla en el área de estudio es la falla Chacalapa, expuesta al norte de Pochutla, que está constituida por ultramilonitas, milonitas, protomilonitas, pseudotaquilitas, filonitas y cataclasitas en orden cronológico de desarrollo. La cinemática de esta zona de cizalla vertical es predominantemente lateral-izquierda.

Las rocas miloníticas de la falla Chacalapa registran temperaturas de recristalización dinámica de $\sim 500^{\circ} \mathrm{C}$ (deformación cristal-plástica de feldespatos) que disminuyen sistemáticamente hasta el régimen netamente quebradizo. Asociadas a la recristalización dinámica se desarrollaron texturas cristalográficas de cuarzo en las rocas miloníticas que, cuando son asimétricas, exhiben un sentido de cizalla izquierdo. Las rocas del régimen quebradizo también registran una cinemática izquierda, al igual que las fallas activas.

La edad de las rocas miloníticas de la falla Chacalapa se ubica entre los $29 \pm 0.2$ y los $23.7 \pm 1.2 \mathrm{Ma}$. El límite de edad superior lo constituye la edad del intrusivo Huatulco (U-Pb de circones, Herrmann et al. 1994) que se observa milonitizado en su margen septentrional y el límite de edad inferior corresponde a la edad K-Ar de hornblenda procedente de diques granodioríticos porfídicos que truncan la milonita.

Palabras clave: Falla, México, Oaxaca, milonita, pseudotaquilita, Xolapa.

\section{Abstract}

Along the coast of Oaxaca between Puerto Angel and Santiago Astata a suite of rocks is exposed corresponding to the Xolapa metamorphic complex which is intruded by granitoid igneous rocks of Paleogene to Miocene age. Both of these rock units are in fault-contact along coast-parallel shear zones with granulite facies metamorphic rocks of the proterozoic age Oaxaca Complex and with cover rocks which unconformably overlie this crystalline basement. The largest of these shear zones is the Chacalapa shear zone exposed to the north of the town of Pochutla and formed by ultramylonites, mylonites, protomylonites, pseudotachylites, phyllonites and cataclasites. The kinematics of this shear zone are dominantly left-lateral. 
The mylonitic rocks of the Chacalapa shear zone indicate temperatures $\sim 500^{\circ} \mathrm{C}$ (as evidenced by crystal-plastic deformation of plagioclase feldspar) which decrease systematically to a strictly brittle deformation regime. Quartz crystallographic textures associated with crystal-plastic deformation processes are locally asymmetric, indicating leftlateral shear. Brittle structures also exhibit left-lateral shear-sense indicators, as do active deformation structures.

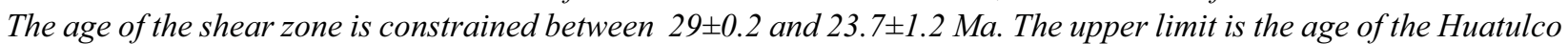
granodiorite (U-Pb from zircon, Herrmann et al. 1994), whose northern contact is sheared, and the lower bound is fixed by the K-Ar age of hornblende separated from granodioritic dikes which cut the mylonitic lineation.

Key words: Fault, Mexico, Oaxaca, mylonite, pseudotachylite, Xolapa.

\section{Introducción}

En el estado de Oaxaca a unos 10 kilómetros al norte del poblado de Puerto Ángel aflora una notoria franja de rocas miloníticas orientada E-W. Esta zona de falla separa rocas en facies de anfibolita del Complejo Xolapa en el sur de rocas en facies de granulita del Complejo Oaxaqueño en el norte y se conoce como falla Chacalapa. La primera descripción de esta falla se encuentra en un resumen de Ortega-Gutiérrez y Corona-Esquivel (1986), quienes la reportaron en las inmediaciones del poblado de San José Chacalapa sobre la carretera Puerto Ángel-Miahuatlán.

La falla Chacalapa se extiende unos 10 kilómetros hacia el poniente de San José Chacalapa donde se bifurca y posteriormente es truncada por rocas intrusivas. Hacia el oriente se extiende unos 40 kilómetros adquiriendo un carácter quebradizo e intersecando la línea de costa del Océano Pacífico. La falla Chacalapa fue tema central de la disertación doctoral de Tolson (1998) quien llevó a cabo la primera cartografía sistemática de la falla así como análisis detallados que se discutirán a continuación.

\section{Marco geológico}

Uno de los aspectos más conspicuos de la geología de México es la presencia de una extensa franja de rocas plutónicas a lo largo de las costas de Guerrero y Oaxaca

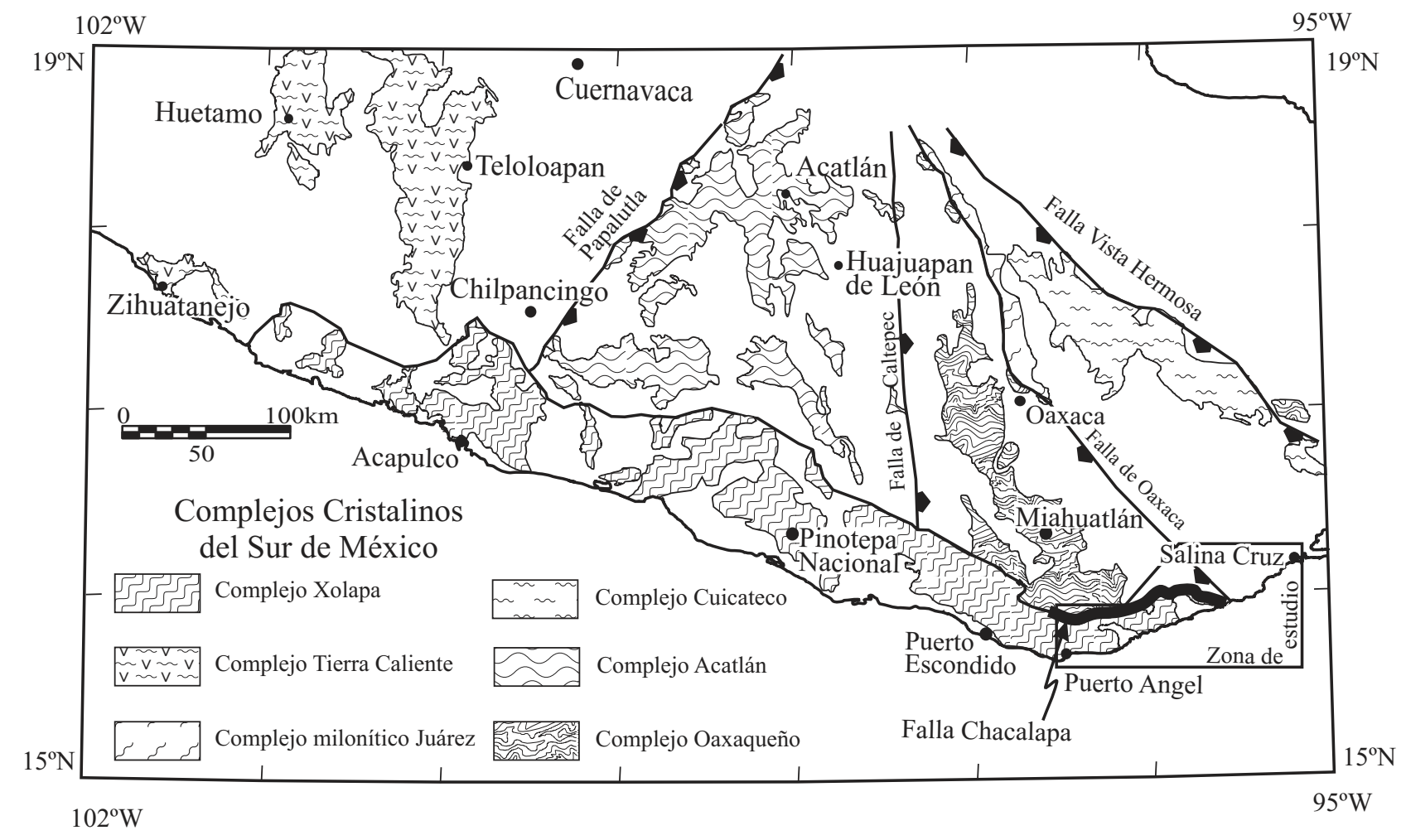

Figura 1. Mapa general del sur de México donde se muestra la distribución de rocas metamórficas y las principales fallas regionales que han sido documentadas (modificado de Sánchez-Zavala, 2005). 
(Figura 1). Estas rocas consisten en orto- y paragneises en facies de anfibolita y de edad incierta cortados por cuerpos batolíticos de composición tonalítica, diorítica y granítica cuyas edades son eocénicas a miocénicas (MoránZenteno, 1992). Las rocas metamórficas que afloran entre Chilpancingo y Acapulco fueron descritas en detalle y definidas estratigráficamente por De Cserna (1965) como Complejo Xolapa de edad paleozoica. El mismo autor describió también rocas graníticas sin deformación regional que cortan el gneis, y comentó el carácter truncado de las estructuras regionales por la línea de costa.

Sánchez-Rubio (1975), Guerrero-García et al. (1978) y posteriormente Ortega-Gutiérrez (1981) resaltaron el contenido de las rocas migmatíticas y ortognéisicas del Complejo Xolapa. Ortega-Gutiérrez (1981) señaló que el complejo basal metamórfico era intrusionado por plutones sin metamorfismo ni deformación regional y dio también una interpretación tectónica al Complejo Xolapa, asentando sus características de metamorfismo de alta temperatura/baja presión y sugirió que se tratara de la porción mesocortical de un arco magmático.

La disertación doctoral de Morán-Zenteno (1992) reportó detalles isotópicos y geocronológicos de las rocas del Complejo Xolapa y de los intrusivos que le afectan al oriente de Acapulco, documentando una edad Jurásico Tardío-Cretácico Temprano para las rocas ortognéisicas del Complejo Xolapa y asignando el plutonismo postmetamórfico al Eoceno-Oligoceno.

Posteriormente, Corona-Chávez (1997) llevó a cabo análisis petrológicos detallados en las rocas del Complejo Xolapa, indicando que se estableció un equilibrio a temperaturas $>650^{\circ} \mathrm{C}$ y a presiones $>7$ kbar durante el pico metamórfico. La historia del truncamiento y de la exhumación de la margen pacífica de México se encuentra resumida sucintamente en Schaaf et al. (1995) y en MoránZenteno et al. (1996).

El límite septentrional del Complejo Xolapa ocurre o bien a lo largo de fallas, como se observa al norte de Acapulco (Riller et al., 1992) y en el área del presente trabajo, o bien a lo largo de intrusivos como en las inmediaciones de Pinotepa Nacional (Hernández-Bernal, 1995; Hernández-Bernal y Morán-Zenteno, 1996).

Hacia la parte septentrional del área de estudio se encuentran aflorando rocas que constituyen el extremo sur del Complejo Oaxaqueño. Estas rocas son una secuencia dominantemente máfica, que contiene franjas alternantes de anfibolita, metagabro y piroxenita. La foliación dominante sigue un rumbo E-W con echados hacia el $\mathrm{S}$ pero su orientación varía localmente y exhibe pliegues de escala variable (micro-, meso- y macroscópicos) con asimetría hacia el norte.

Las rocas félsicas del basamento metamórfico de esta región han sido consideradas previamente como anortosita de tipo alcalino (Herz, 1978) y muestran evidencia de emplazamiento sincinemático. Están constituidas por un mosaico de plagioclasa de composición intermedia (andesina) y lentes de megacristales deformados con textura antipertítica. El contenido de cuarzo es muy variable y se le encuentra en proporciones que varían desde trazas hasta un $30 \%$. Se observan además, rutilo, ilmenita, y apatita diseminados. En algunas zonas las concentraciones de titanio llegan a ser importantes desde un punto de vista económico, formando yacimientos como el de Pluma Hidalgo, al norte de Pochutla (Paulson, 1969). En general, hay una variación en el índice de color de las rocas que es controlada por el contenido de cristales sub- a euédricos de clinopiroxenos, los cuales se presentan cloritizados y tremolitizados.

Alternando con los cuerpos de roca anteriores, se encuentran franjas de anfibolita, en ocasiones con piroxeno y granate, metagabro de augita y diópsido que contienen localmente bandas hasta de $10 \mathrm{~cm}$ de piroxenita de clinopiroxeno en parte cloritizado. La secuencia metamórfica es cortada por una generación de diques máficos a intermedios, afaníticos o porfídicos, que no presentan deformación en el régimen cristal-plástico alguna (Figura 2).

En el área de estudio, el Complejo Oaxaqueño está cubierto en discordancia angular por un paquete de andesita basáltica, cubierto por una secuencia de conglomerado seguido por arenisca con intercalaciones de conglomerado. Es característico en este paquete un color verde en roca fresca que intemperiza a marrón con tonos de morado. La arenisca es cubierta concordantemente por brecha calcárea que a su vez le sobreyace caliza masiva que forma los altos topográficos de la región. La caliza no contiene fósiles índice y durante este estudio sólo se reconocieron restos de pelecípodos y gasterópodos. Esta secuencia estratigráfica es muy similar a la descrita en un reporte interno de PEMEX (1986) donde correlacionan las rocas carbonatadas con la formación Teposcolula de edad Albiano-Cenomaniano.

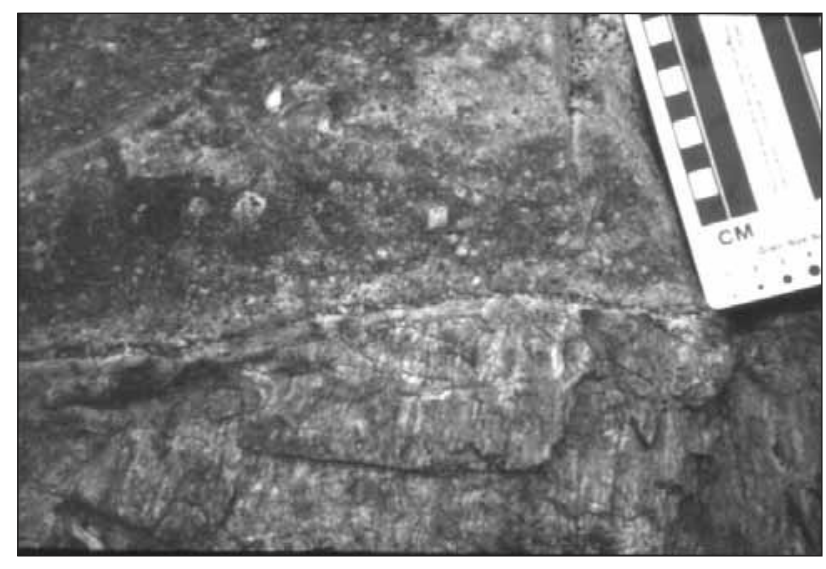

Figura 2. Dique porfídico cuarzodiorítico con hornblenda (arriba) cortando rocas miloníticas de la zona de cizalla Chacalapa (abajo, con lineación subvertical en la foto) en el lecho del río Huatulco, $1 \mathrm{~km}$ aguas arriba del puente Paso Ancho al norte del poblado de Santa María Huatulco. 
Las rocas de esta secuencia también son afectadas por el sistema de falla Chacalapa en la zona de estudio y exhiben metamorfismo en facies de esquistos verdes.

\section{Geología estructural}

La geología estructural del área es compleja, ya que incluye una falla de escala regional que pone en contacto dos paquetes metamórficos que a su vez se caracterizan por una historia de múltiples eventos de deformación. Los distintos episodios de deformación se manifiestan mediante estructuras del régimen cristal-plástico, transicional y frágil con relaciones de corte que permiten establecer su cronología relativa.

\subsection{Estructuras regionales}

La estructura regional de mayor importancia en el área de estudio es la falla Chacalapa con rumbo general E-W que yuxtapone las rocas del Complejo Oaxaqueño (y su cobertura) con las del Complejo Xolapa. Esta discontinuidad tectónica se extiende más de 50 km a rumbo.
Tiene características de deformación en el régimen dúctil, con desarrollo de milonitas con texturas de recristalización dinámica en estado sólido, y de deformación en el régimen quebradizo con desarrollo de pseudotaquilitas, cataclasitas y salbandas. La zona de cizalla es continua a rumbo desde el occidente del poblado de Chacalapa (LazosRamírez y Rodríguez-Rivera, 1995) hasta el oriente de Santa María Xadani, pero en las cercanías del poblado de Xuchil, adquiere un carácter trenzado o anastomosado, bifurcándose alrededor de bloques de los complejos Oaxaqueño y Xolapa no milonitizados (Figuras 3 y 4). El espesor de las zonas miloníticas varía desde cientos de metros donde se encuentra trenzada, hasta $\sim 2 \mathrm{~km}$ en las cercanías del pueblo de Santa María Huatulco. Esta zona milonítica es posterior a una serie de zonas de cizalla que se encuentran en rocas del Complejo Xolapa con espesores de decenas de metros y extensiones de 1 a $2 \mathrm{~km}$ con texturas de carácter netamente dúctil; la traza en planta de estas estructuras es más compleja que la de la falla Chacalapa, ya que sus inclinaciones son moderadas a bajas.

Por otra parte existen también una serie de fallas con desplazamiento oblicuo lateral-normal evidentes tanto en imágenes de satélite, como en fotografías aéreas, como en el campo. Algunas de estas fallas son activas como lo sugiere

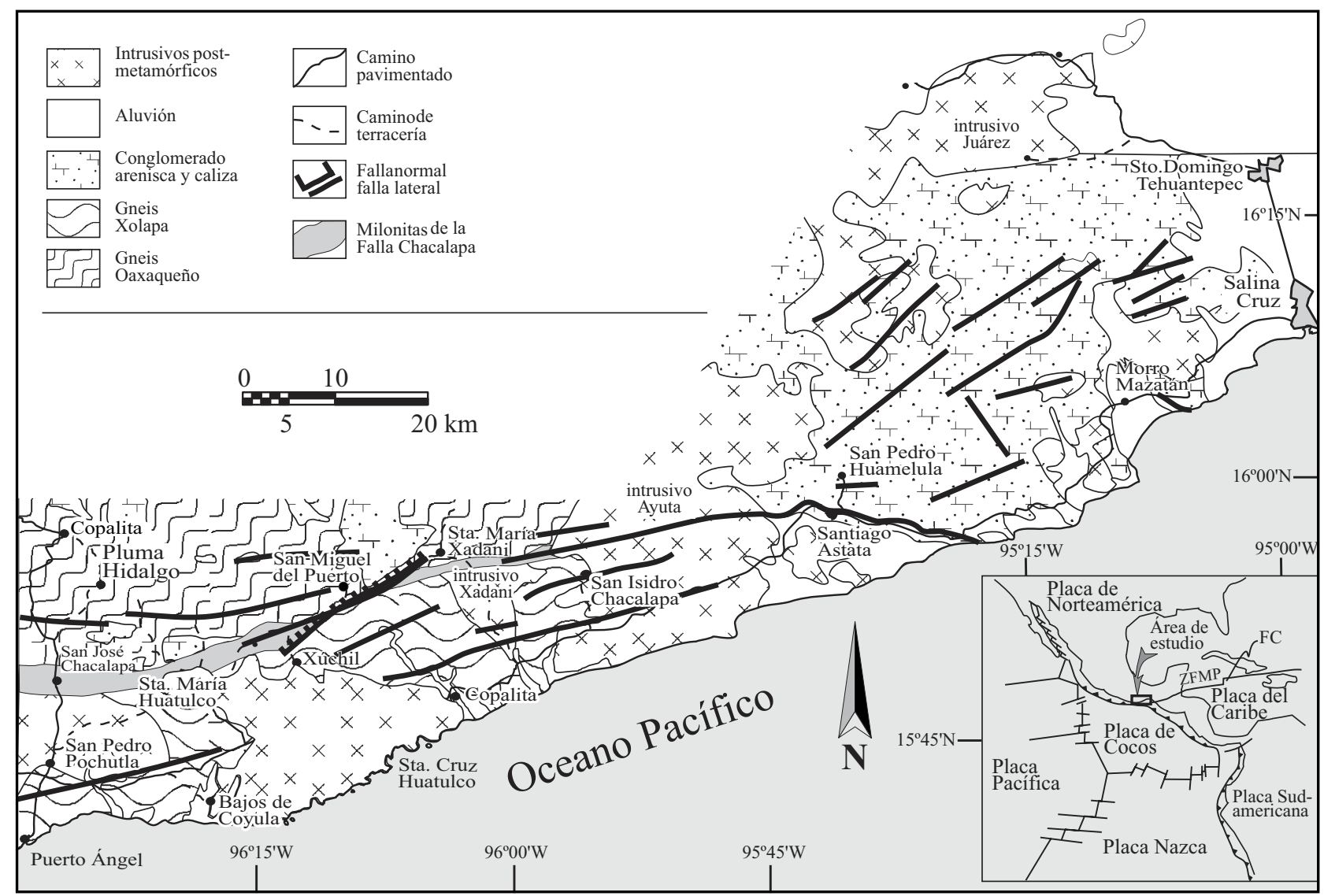

Figura 3. Mapa geológico del área de estudio. La porción nororiental está modificada del mapa de Carfantan (1986). El recuadro muestra la ubicación del área en el marco tectónico (modificado de Morán-Zenteno et al., 1996). FC se refiere a la fosa Caymán y ZFMP se refiere a la zona de fallas Motagua-Polochic. 


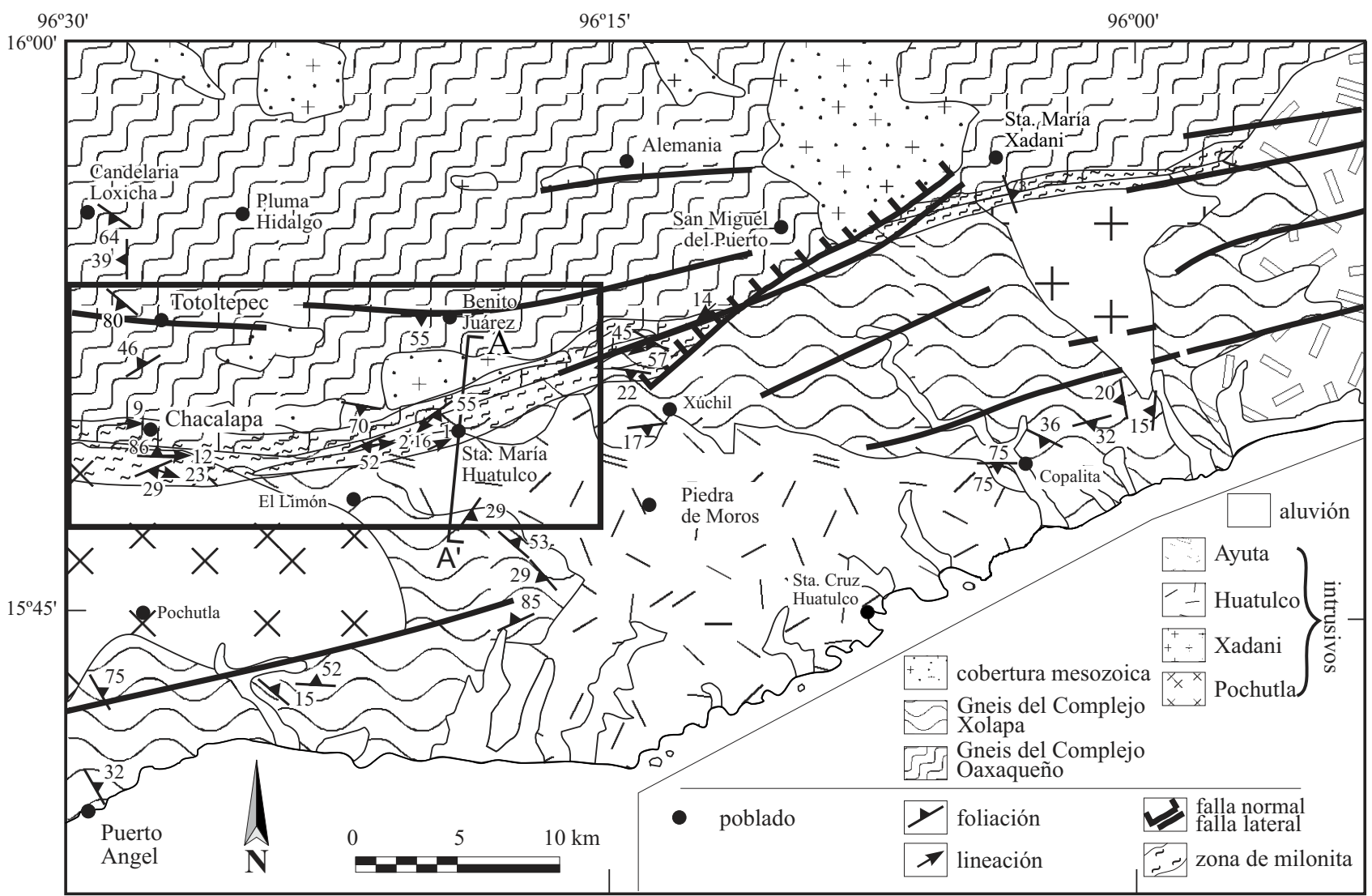

Figura 4. Detalle del mapa geológico del área de estudio. Esta área se cartografió a escala 1:50,000. El recuadro ubica el área que se muestra en la Figura 7.

el desplazamiento de estructuras civiles (Delgado-Argote y Carballido-Sánchez, 1990).

\subsection{Estructuras mesoscópicas}

El área estudiada se puede subdividir en cuatro dominios estructurales: el dominio del Complejo Oaxaca y sus rocas de cobertura hacia el norte, el dominio del Complejo Xolapa hacia el sur, la falla Chacalapa que forma el contacto entre ambos y finalmente las rocas de bajo grado metamórfico del "Arco Chontal" de Carfantan (1983) en la porción nororiental de la zona de estudio (Figura 5). Los dominios Oaxaca y Xolapa se caracterizan principalmente por estructuras planares, en particular la presencia de foliación gnéisica penetrativa en escala de centímetros, definida por alternancias de minerales claros y obscuros. En las rocas del Complejo Xolapa esta foliación fue afectada por una deformación tardo-migmatítica que se manifiesta en zonas miloníticas de espesor decamétrico claramente truncadas por la falla Chacalapa; estas zonas miloníticas no son el tema central del presente trabajo y sólo se mencionarán en el contexto evolutivo del Complejo Xolapa. El dominio milonítico de la falla Chacalapa, en cambio, ha desarrollado una fuerte lineación, L, de extensión mineral mientras que la foliación puede ser débil o más comúnmente ausente.

La zona milonítica había sido previamente descrita en su segmento oriental por Ortega-Gutiérrez y CoronaEsquivel (1986) y cartografiada por Ortega-Gutiérrez et al. (1990) en el sector Puerto Escondido, Puerto Ángel. Regionalmente la traza de la falla presenta una curvatura aproximadamente paralela a la costa (Figura 1) que varía en su rumbo de WNW a ENE. Existe también una tesis de licenciatura en la cual se describe con mucho detalle cartográfico y microscópico la zona milonítica desde San José Chacalapa hacia el oriente, donde se documenta también el carácter trenzado de la zona de deformación (Lazos-Ramírez y Rodríguez-Rivera, 1995).

La proyección equiareal de polos de foliación del dominio Xolapa muestra una guirnalda de círculo mayor orientada verticalmente norte-sur, lo cual indica que la foliación ha sido plegada alrededor de un eje horizontal este-oeste (Figura 5). Existe una ligera asimetría en la distribución de los planos, lo que sugiere una vergencia hacia el norte. Esta vergencia es acorde a la observación de zonas de cizalla tabulares de extensión limitada (cientos de metros a rumbo) orientadas más o menos E-W (075$\left.095^{\circ}\right)$, con inclinaciones moderadas $\left(20-75^{\circ}\right)$ al sur y con indicadores cinemáticos de sobrecorrimiento hacia el norte. 


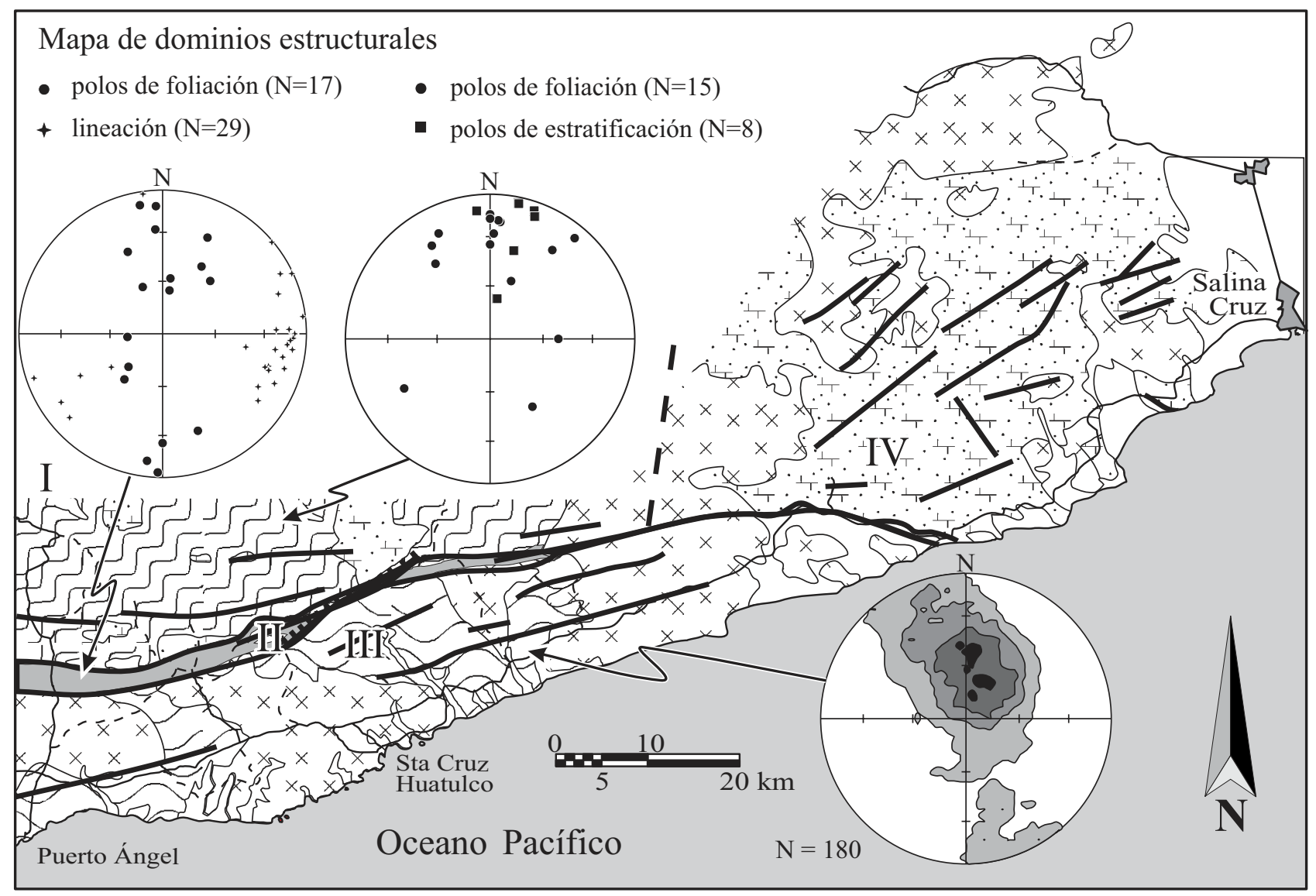

Figura 5. Mapa con los límites entre los dominios estructurales definidos en el presente estudio. El dominio I consiste principalmente de gneises granulíticos del Complejo Oaxaqueño y su cobertura. El dominio II lo constituyen milonitas fuertemente lineadas de la zona de cizalla Chacalapa. El dominio III consiste en gneises localmente migmatíticos del Complejo Xolapa e intrusivos oligocénicos. El dominio IV corresponde a una secuencia supracortical fuertemente plegada.

La proyección de polos de foliación del dominio Oaxaqueño muestra que la foliación tiene una orientación preferencial con rumbo E-W e inclinación moderada a fuerte al sur (Figura 5). Los polos de planos de estratificación de las rocas de la cobertura del Oaxaqueño son subparalelos a los de la foliación gnéisica.

La red equiareal de los polos de foliación milonítica y las lineaciones de extensión, muestran que las foliaciones miloníticas son en general subparalelas a las de los dominios Oaxaqueño y Xolapa, y que las lineaciones están contenidas en el plano de foliación siendo subhorizontales y con dirección E-W (Figura 5). La sección mejor expuesta de milonita es la que aflora a lo largo del cauce del río Huatulco entre Santa María Huatulco y Benito Juárez. En esta sección se observa claramente la transición de rocas graníticas sin deformar del intrusivo Huatulco, hasta ultramilonitas con lineación de extensión mineral penetrativa en escala milimétrica. Esta transición es gradual y compleja: el granito fresco empieza a ser afectado por pares de fallas conjugadas con distancias aproximadas entre los pares de $20 \mathrm{~m}$ y orientaciones NNW-SSE y NE-SW. La densidad de las fallas aumenta paulatinamente, así como su espesor, conforme desarrollan una zona de salbanda y brechas con una distintiva coloración azul-gris. Los planos de falla no exhiben lineaciones que indiquen el movimiento relativo entre los bloques, pero las relaciones de corte entre fallas sugieren que son pares izquierdos-derechos. La separación entre fallas continúa disminuyendo hasta que llega a ser de centímetros. A partir de ese punto, la roca adquiere una apariencia sumamente fracturada y su color se torna más obscuro a raíz de la intensa molienda en ciertos sectores. En una distancia del orden de metros, se hace evidente la presencia de una lineación de extensión y las fallas se vuelven escasas. Esta última constituye la transición final y, a partir de este punto, la roca se transforma en una milonita franca. En total, la secuencia de transición tiene un espesor de $300 \mathrm{~m}$ sobre el lecho del río. Esta secuencia indica que la misma traza de zona de cizalla ha sido reactivada con fallamiento en régimen quebradizo, lo cual a su vez indica la exhumación progresiva de la zona de cizalla.

Dentro del granito milonitizado se pueden ver xenolitos de metasedimento del Complejo Xolapa alargados paralelos a la lineación mineral. Al avanzar hacia el norte, aumentan los xenolitos de tamaño decimétrico a métrico y 
finalmente el granito se encuentra sólo en apófisis dentro de los metasedimentos milonitizados. Esto sugiere que la zona de milonita en esta localidad es subparalela al contacto del granito con la roca encajonante. El desarrollo de las estructuras miloníticas es acompañado por un aumento en el contenido de muscovita en el granito que puede ser debido a una de dos razones: la reacción, en presencia de agua, de feldespato potásico a cuarzo + muscovita que frecuentemente se observa en zonas de milonita y que corresponde a presiones de $\mathrm{H}_{2} \mathrm{O}$ mayores a $3.5 \mathrm{kbar}$ (Simpson y De Paor, 1991); o bien pudiera ser el resultado de la asimilación de metasedimentos del Complejo Xolapa en la periferia del intrusivo Huatulco, que le impartiría una composición más aluminosa manifestándose con el crecimiento de cristales de muscovita.

En otra sección, al sur de San Miguel del Puerto, afloran rocas protomiloníticas del Complejo Oaxaqueño afalladas e intrusionadas por pseudotaquilita. Más al oriente de esta localidad en la ribera derecha del río Copalita, afloran vetas de pseudotaquilita con espesores hasta de $30 \mathrm{~cm}$. A lo largo de la falla a la cual están asociadas estas pseudotaquilitas, el río Copalita exhibe un desplazamiento aparente de 3.0 $\mathrm{km}$.

Para la estimación de distorsión se utilizaron los métodos NewFry (Tolson, 1996) y Retrodeformación de imágenes digitales (Weger, 1996). El método NewFry se utilizó para las rocas de bajo grado de deformación correspondientes a la cobertura mesozoica y el método de retrodeformación de imágenes se aplicó a dominios de plagioclasa de las rocas miloníticas. Los resultados de estimación de distorsión se presentan en un diagrama de Flinn logarítmico en la Figura 6. Las orientaciones y formas de las elipses XY y XZ también están representadas en la Figura 7, incisos a y b, respectivamente. El diagrama de Flinn muestra que la forma de los elipsoides determinados cae en el campo de los elipsoides prolados, lo cual es corroborado en campo por las características de la tectonita L con lineación predominante. En un sistema de zona de cizalla general (con combinaciones de cizallas pura y simple) los elipsoides prolados corresponden a un sistema transtensivo, ya que aún a distorsiones internas fuertes la lineación sigue siendo horizontal. Esto no sucede en un sistema transpresivo, ya que la dirección de máxima extensión cambia de ser horizontal a vertical con el aumento de la distorsión interna y los elipsoides resultantes son oblados (Fossen y Tikoff, 1993).

\subsection{Estructuras microscópicas}

Desde el punto de vista microscópico, las rocas estudiadas contienen una variedad de estructuras que incluyen: esquistosidad, gneisosidad, orientación preferencial de agregados granulares, orientación preferencial de ejes cristalográficos, porfidoclastos $\delta$ y $\sigma$, peces de mica, y estructuras S-C (Figuras 8a y 8b).

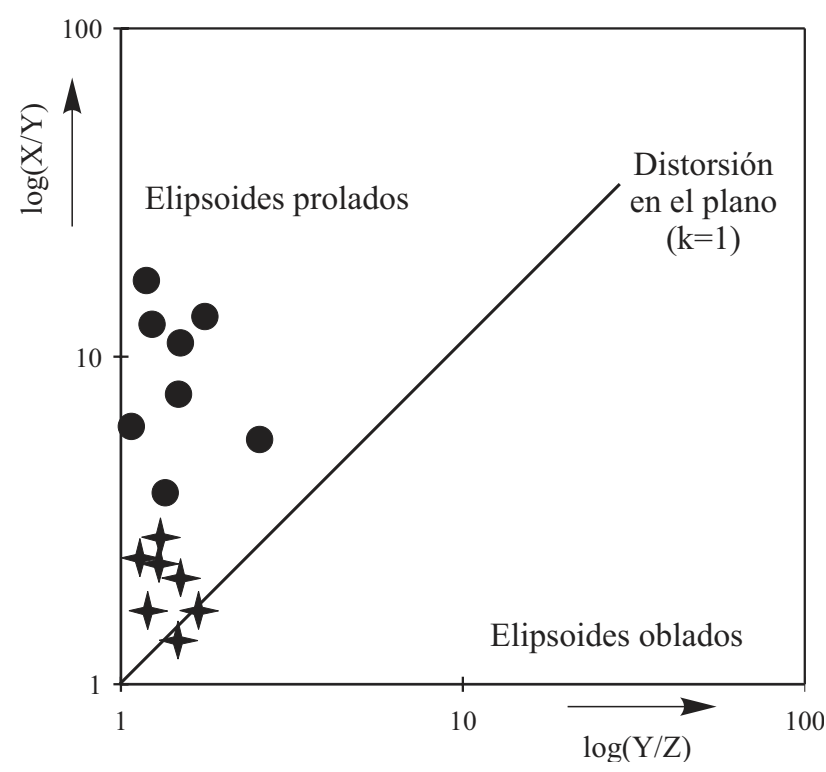

Figura 6. Gráfico logarítmico de Flinn con los puntos correspondientes a rocas de la zona de falla Chacalapa calculados en el curso del presente estudio. Los datos con círculo fueron estimados con el método de Weger (1996) y aquellos con estrella con el método NewFry. Nótese que, en general, las muestras se restringen al campo de elipsoides prolados.

La esquistosidad es definida por el paralelismo de hojuelas de biotita y muscovita en las rocas metasedimentarias no migmatizadas del Complejo Xolapa y es, en general, paralela a la gneisosidad definida por alternancias de minerales cuarzo-feldespáticos y máficos en las rocas migmatíticas y ortognéisicas del complejo. Aparte de pequeñas crenulaciones de las micas, que se observan localmente, tanto en gneises como en esquistos, la gneisosidad y la esquistosidad no aportan información que no haya sido previamente discutida en la sección anterior.

La orientación preferida de formas granulares y de orientaciones cristalográficas, en cambio, tienen implicaciones importantes sobre las condiciones termobáricas durante la deformación. Las rocas que exhiben orientación preferida de formas granulares y de orientaciones cristalográficas son las milonitas graníticas del intrusivo Huatulco. Estas rocas muestran al microscopio las mismas gradaciones en deformación que se observan en los afloramiento al aproximarse a la zona de cizalla. Las muestras que provienen de afloramientos más distantes del centro de la zona de cizalla, muestran evidencia de deformación en régimen quebradizo, pudiéndose ver plagioclasas fracturadas, zonas de molienda, y vetillas rellenas de material secundario como calcita y epidota. Las muestras de granito provenientes de la zona media de la franja milonítica, en cambio, tienen cristales de plagioclasa cuyas maclas están deformadas de manera dúctil, y cristales de cuarzo que se ven completamente recristalizados, con uniones triples de $120^{\circ}$, sin extinción ondulante, y con fuerte paralelismo de los ejes ópticos. Siguiendo criterios definidos por Tullis 

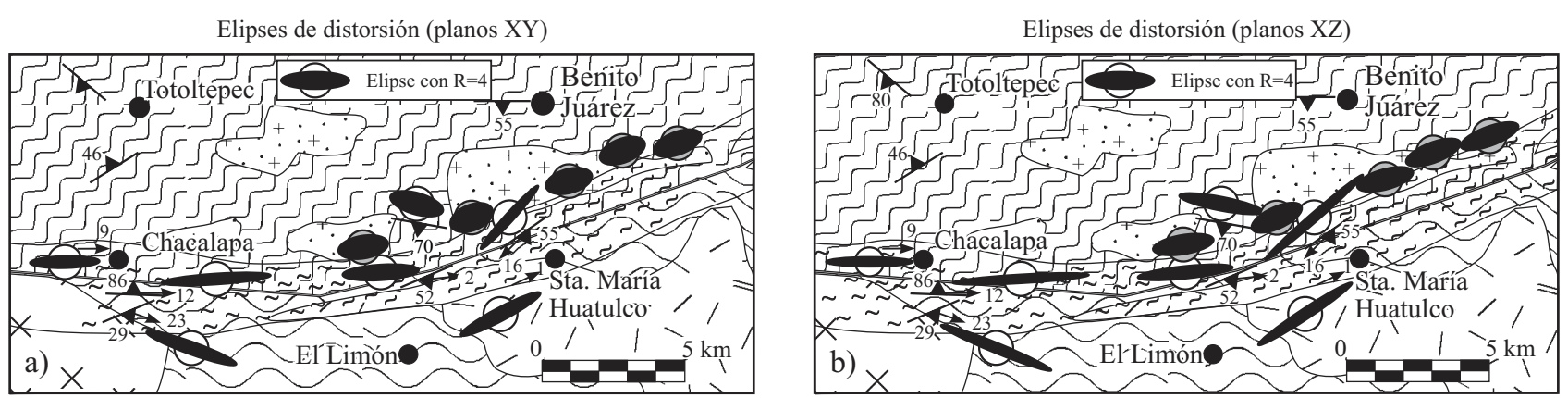

Figura 7. a) Ubicación de elipses de distorsión medidas en el plano XY del elipsoide de distorsión interna. b) Ubicación de elipses de distorsión medidas en el plano XZ del elipsoide de distorsión interna. En ambos mapas los elipses con círculos de referencia blancos fueron estimados con el método de Weger (1996) y los grises con el método NewFry (Tolson, 1996). Para la leyenda véase la Figura 4.

(1977) y Hirth y Tullis (1992), estas texturas microscópicas sugieren un régimen de deformación cuya temperatura es mayor de $\sim 500^{\circ} \mathrm{C}$. Las texturas cristalográficas del cuarzo muestran tanto círculos menores alrededor del eje de máximo acortamiento, como máximos lineales oblicuos a la foliación (Tolson et al., 1993) (Figura 9). Las texturas de círculos menores son comunes en rocas con elipsoides de deformación oblados (Lister y Dornsiepen, 1982) y los máximos oblicuos pudiesen interpretarse como resultado de desliz basal en dirección $<1000>$. Las dos texturas han sido reportadas en terrenos donde la deformación ocurrió a temperaturas $>500^{\circ} \mathrm{C}$. La recristalización dinámica de plagioclasa y su deformación cristal-plástica son acordes a temperaturas en este rango (Passchier y Trouw, 1996).

También asociadas a la falla Chacalapa se observan milonitas que exhiben evidencia de haberse formado bajo condiciones fisicoquímicas correspondientes a la facies de esquistos verdes. En estas rocas la paragénesis albita + epidota \pm clorita es característica y se observa directamente asociada a los procesos de deformación (Figura 10).

\subsection{Desarrollo estructural}

Localmente, las migmatitas del complejo Xolapa incluyen vestigios paleosomáticos, de composición pelítica a anfibolítica, embebidos en un neosoma granítico. Estos vestigios exhiben evidencia de una deformación penetrativa en escala de centímetros anterior a la fusión parcial que generó las migmatitas del complejo Xolapa (Figura 11). Este evento constituye la deformación más antigua que registran las rocas del Complejo Xolapa en la zona de estudio aquí denominado $D_{n}$. El segundo evento de deformación $\left(D_{n+1}\right)$ coincide en el tiempo con la intrusión de los ortogneises sincinemáticos documentados por Morán-Zenteno (1992) y es el responsable del desarrollo de foliaciones en las rocas encajonantes paralelas a las foliaciones magmáticas que se observan en los ortogneises. El siguiente evento deformacional $\left(\mathrm{D}_{\mathrm{n}+2}\right)$ fue penecontemporáneo con el evento migmatítico y existe evidencia de su continuación en tiempos inmediatamente posteriores a la migmatización. La evidencia la constituyen, por ejemplo, las franjas miloníticas con trazas curvas con rumbos más o menos E-W e inclinaciones bajas a moderadas al sur e indicadores cinemáticos que sugieren sobrecorrimientos dirigidos hacia el norte. Estas zonas de cizalla tienen la misma vergencia
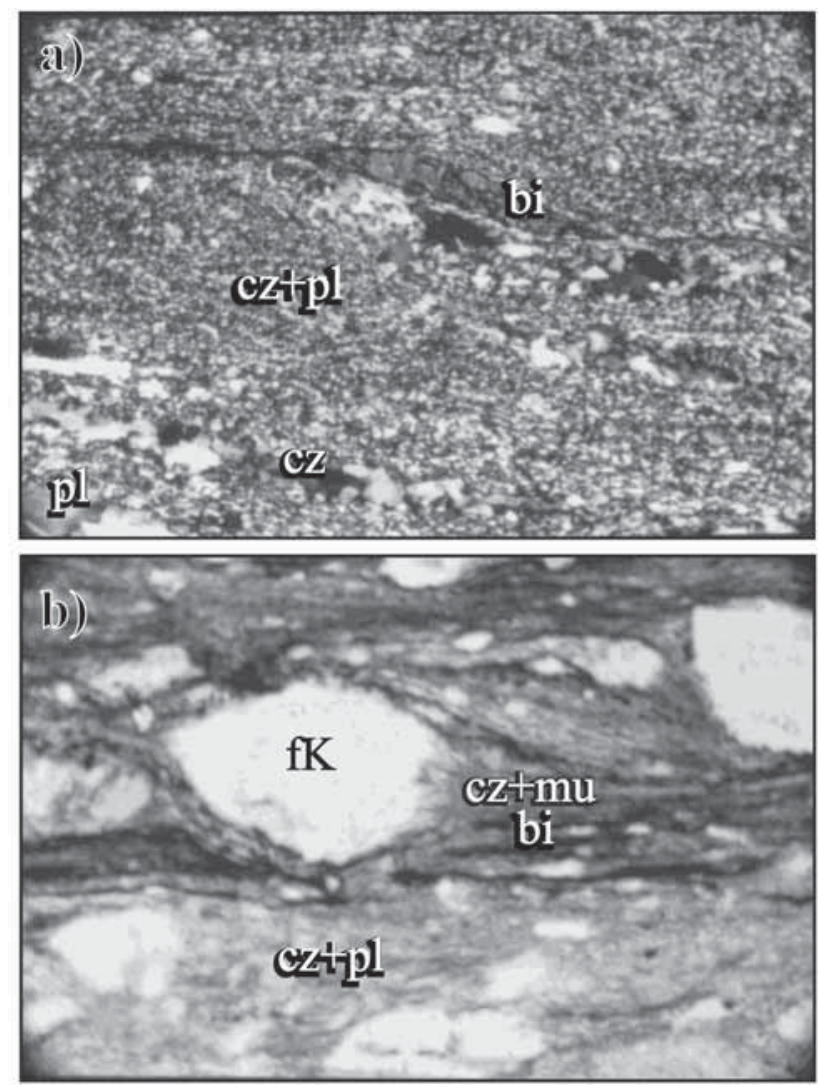

Figura 8. a) Pez de biotita en una ultramilonita del lecho del río Huatulco en las cercanías de Santa María Huatulco. Es clara la cinemática izquierda. b) Porfidoclasto $\sigma$ en protomilonita de paragneises del Complejo Xolapa que afloran en el lecho del arroyo Xuchil al norte del poblado del mismo nombre. Nuevamente queda sin ambigüedad la cinemática izquierda. Las abreviaciones son: $\mathrm{bi}=$ biotita, $\mathrm{cz}=$ cuarzo, $\mathrm{pl}=$ plagioclasa, $\mathrm{fK}=$ feldespatopotásico, $\mathrm{mu}=$ muscovita. 


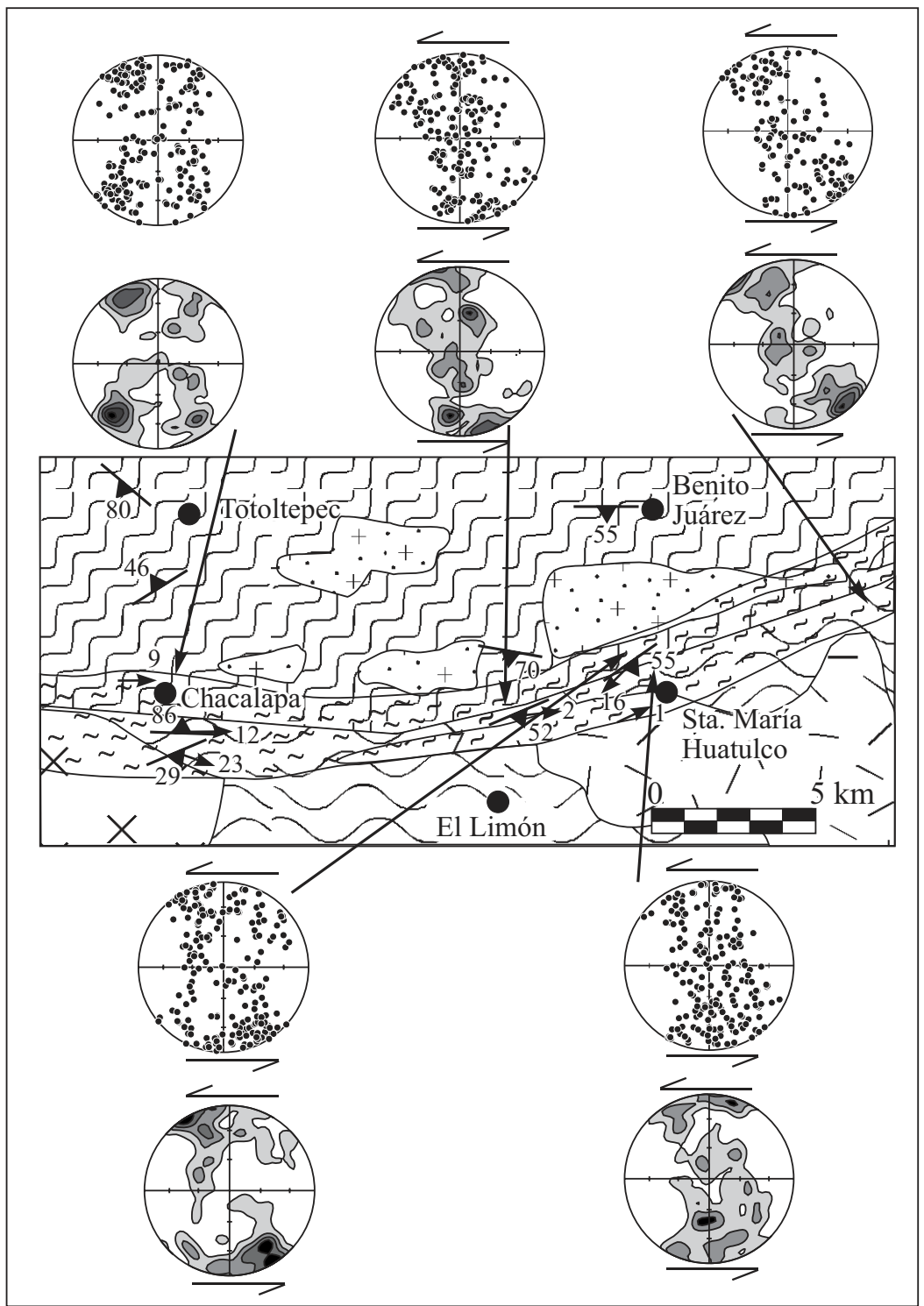

Figura 9. Ejes cristalográficos de cuarzo de las rocas miloníticas de la zona de cizalla Chacalapa. Para la leyenda véase la Figura 4.

que la asimetría de los pliegues que afectan la foliación gnéisica asociada a las migmatitas y es contemporánea. Asociadas también a los pliegues, existen estructuras de intrusión local de material móvil que fueron posteriormente involucrados en el plegamiento. La cuarta fase $\left(D_{n+3}\right)$ de deformación firmemente documentada es la asociada al régimen tectónico transtensional y a la falla Chacalapa. Esta fase de deformación afectó progresivamente a las rocas del terreno Xolapa de manera tanto dúctil como quebradiza en escala de afloramiento, de tal manera que tenemos el desarrollo de rocas miloníticas (deformación cristal-plástica) en facies de anfibolita, esquistos verdes y la formación de pseudotaquilitas y cataclasitas.

Las edades absolutas para estos eventos de deformación son aún desconocidas, pero están bastante constreñidas con respecto a algunos eventos magmáticos que se han podido fechar. El evento premigmatítico $\mathrm{D}_{\mathrm{n}}$ debe ser pre-Cretácico Temprano si consideramos la edad de las rocas ortognéisicas del Complejo Xolapa obtenida por Morán-Zenteno (1992) como correcta. Por otra parte, si las edades discordantes de $\mathrm{U} / \mathrm{Pb}$ reportadas por Herrmann et al. (1994) son correctas, entonces $\mathrm{D}_{\mathrm{n}}$ podría ubicarse hasta el Cretácico terminal. También se puede ubicar el evento $\mathrm{D}_{\mathrm{n}+2}$ en el Cretácico Temprano o el Paleoceno-Eoceno medio dependiendo de la edad que uno considere correcta. En cambio, el evento milonítico transtensional $\mathrm{D}_{\mathrm{n}+3}$ sucedió entre 29 y $23.7 \mathrm{Ma}$ (Tolson 1998), ya que el tronco Huatulco es afectado por cizalla y la foliación milonítica es truncada por diques de composición dacítica y hornblenda separada de éstos arrojó la edad inferior (Figura 2). La deformación en el área de estudio continúa hoy en día a lo largo de fallas activas de desplazamiento lateral izquierdo. 


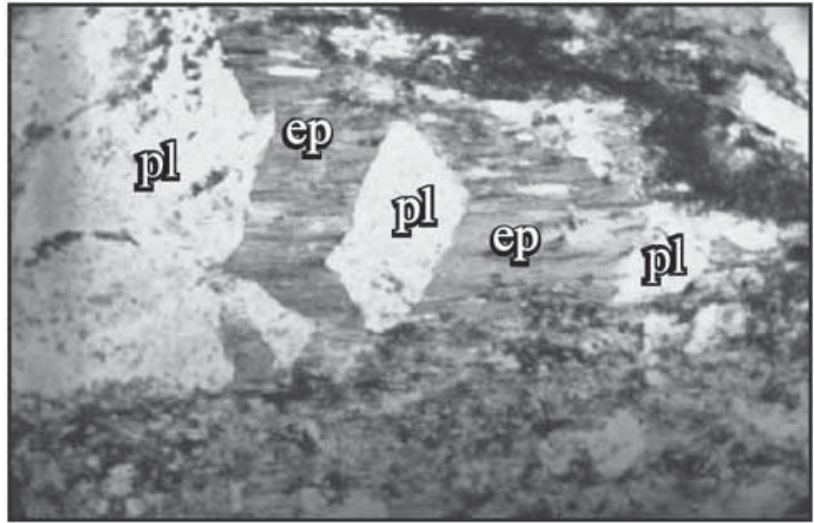

Figura 10. Fotomicrografía de la protomilonita Chacalapa mostrando la fragmentación de un cristal de plagioclasa $(\mathrm{pl})$ con el crecimiento de fibras de epidota (ep) entre los fragmentos. Nótese que se puede restituir la forma inicial del cristal de plagioclasa (anchura del campo $2 \mathrm{~mm}$; luz paralela).

\subsection{Cinemática}

En el curso del presente estudio se documentaron dos fases de desarrollo de zonas miloníticas. El primer evento sucedió en las etapas tardías del evento migmatítico del Complejo Xolapa y muestra la misma vergencia que la asimetría de los pliegues de foliación migmatítica. Las zonas de cizalla asociadas a este evento son irregulares en planta y tienen inclinaciones fuertes a moderadas hacia el sur. Estas zonas de cizalla son las que mejor exhiben el desarrollo de estructuras S-C, quizás caracterizando la naturaleza más transpresiva de este evento en contraste con las rocas de deformación transtensiva del dominio correspondiente a la falla Chacalapa.

Los porfidoclastos $\delta$ y $\sigma$, asociados a la falla Chacalapa, son notables en las rocas metasedimentarias del Complejo Xolapa y en algunos gneises del Oaxaqueño. Los peces de mica son comunes en la mayoría de las rocas miloníticas, mientras que las texturas S-C escasean en general dado que la tectonita es dominantemente de tipo L (Turner y Weiss, 1963). Todos estos indicadores cinemáticos del régimen dúctil acusan una cizalla izquierda a rumbo. Por otra parte, las texturas cristalográficas medidas en algunas muestras de la zona milonítica refuerzan esta interpretación cinemática, ya que poseen guirnaldas oblicuas a la lineación con una asimetría que indica también movimiento izquierdo, aunque cabe mencionar que hay también texturas que indican cizalla pura (Figura 9). Las fallas del régimen quebradizo también exhiben una cinemática izquierda dominante (Figura 12), aunque también se han observado fallas normales con desplazamientos importantes.

\section{Discusión y conclusiones}

Si bien, como se ha demostrado, la edad, geometría y cinemática de la falla Chacalapa están bien constreñidas,

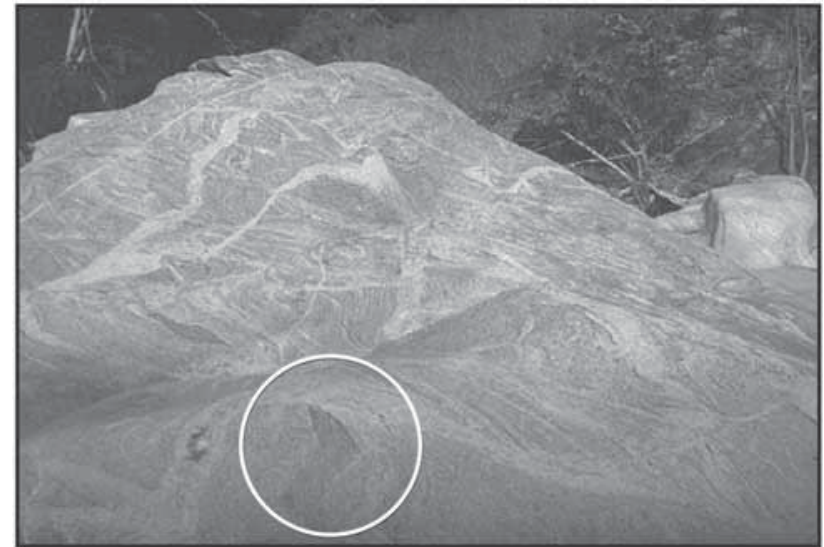

Figura 11. Fotografía de afloramiento de gneises migmatíticos del complejo Xolapa. En primer plano se observa una reliquia anfibolítica con una foliación preexistente plegada de manera isoclinal. Notense las distintas generaciones de material neosomático.

su interpretación en términos tectónicos es aún incierta. Lo cierto es que la falla Chacalapa limita rocas granulíticas del Complejo Oaxaqueño y su cobertura sedimentaria, por un lado, de las rocas mesocorticales del Complejo Xolapa, por el otro. Por este motivo, las propuestas iniciales sugerían que este límite tectónico corresponde a una falla de
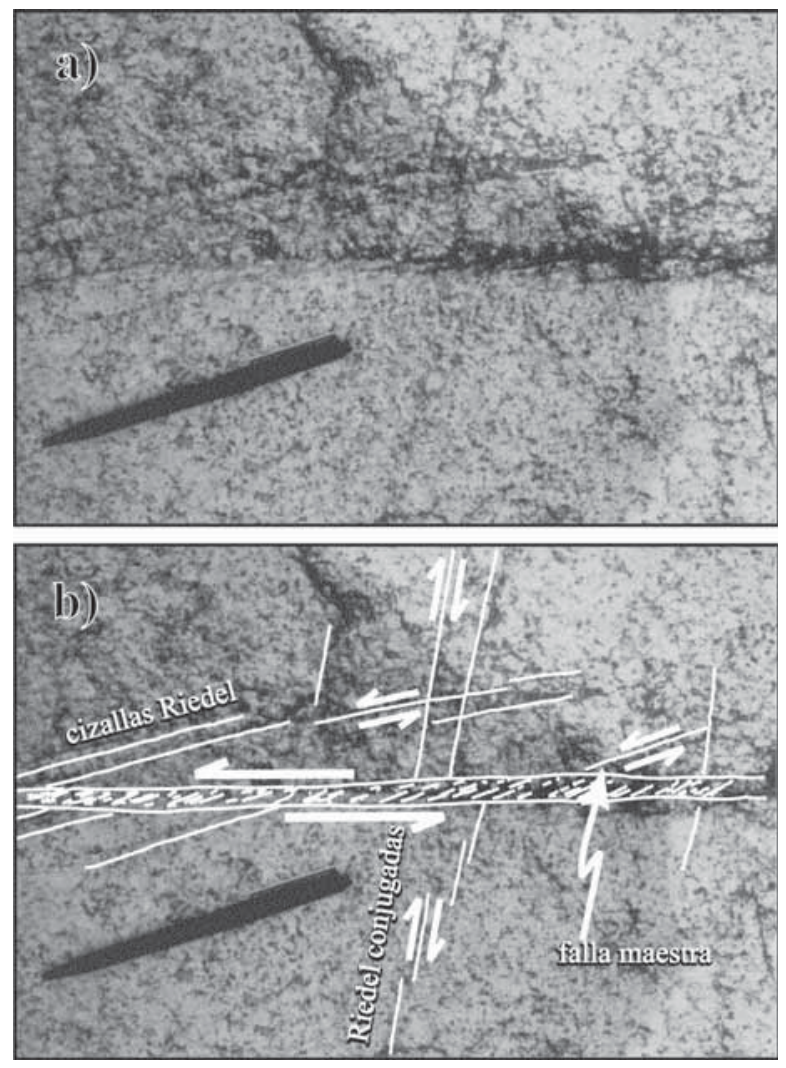

Figura 12. Indicadores cinemáticos del régimen quebradizo en rocas graníticas del intrusivo de Ayuta. 
exhumación similar a las fallas asociadas con los núcleos metamórficos de la Cordillera americana (Robinson et al., 1989). Estas consideraciones de similitud se basaban en aspectos un tanto superficiales y cualitativos de la geología de los bordes septentrionales del Complejo Xolapa, particularmente la yuxtaposición de rocas con deformación en régimen quebradizo con rocas deformadas en el régimen cristal-plástico.

Esta propuesta fue madurando e incorporándose a modelos tectónicos que invocaban la presencia del bloque Chortis frente a las costas de Guerrero y su posterior desplazamiento hacia su posición actual (Meschede, 1994; Morán-Zenteno et al., 1996). Este modelo es apoyado por los datos geocronológicos de rocas cristalinas a lo largo de la costa pacifica mexicana, desde Pto. Vallarta, Jalisco, hasta Salina Cruz, Oaxaca (Morán-Zenteno et al., 2000). Los datos muestran una tendencia general de disminución de las edades hacia el sureste, y se pueden reconocer dos tendencias más o menos lineales lo cual se ha citado a favor de la paulatina extinción del magmatismo al cambiar el régimen tectónico de un límite tectónico lateral distensivo a un régimen de subducción ligeramente oblicuo (Figura 13).

En fechas más recientes, los trabajos de Ducea et al. $(2004,2005)$ han cuestionado y aumentado la base de datos

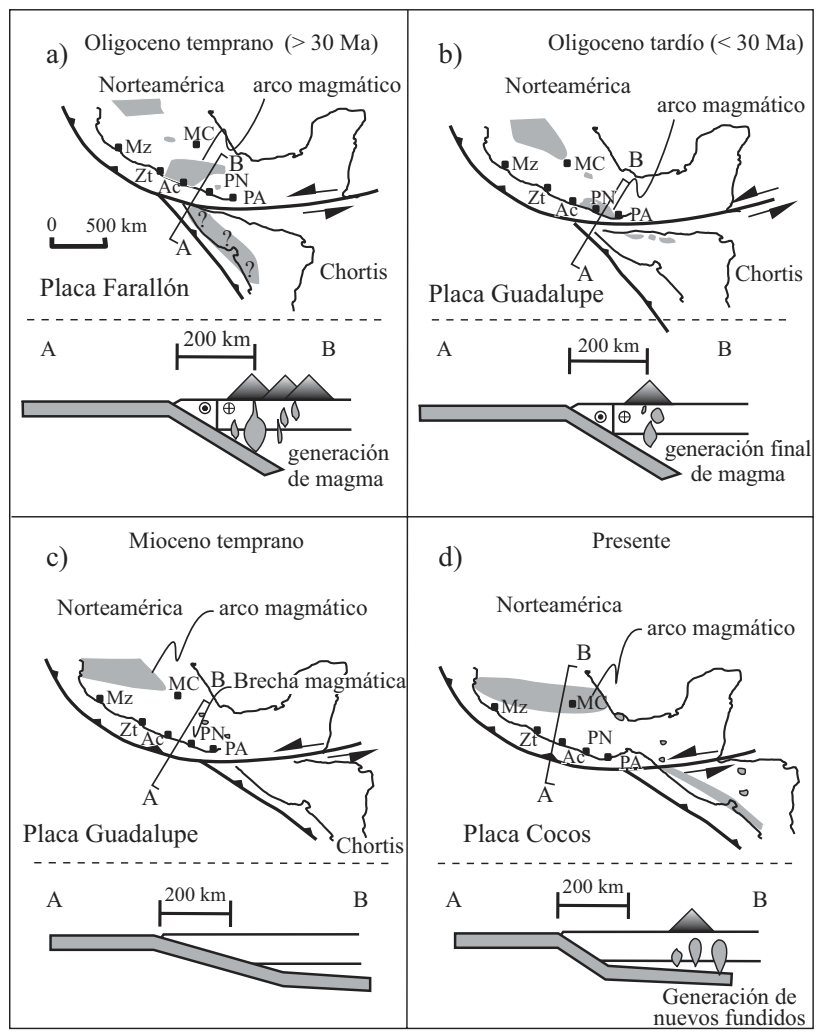

Figura 13. Modelo tectónico evolutivo del sur de México desde el Oligoceno mostrando la evolución de patrones de actividad ígnea. Las abreviaciones son: $\mathrm{Ac}=$ Acapulco, $\mathrm{MC}=$ Méxic, $\mathrm{Mz}=$ Manzanillo, $\mathrm{PA}$ $=$ Puerto Ángel, $\mathrm{Zt}=$ Zihuatanejo. geocronológicos de la región, al grado de poner en tela de juicio dichas interpretaciones. Estos autores proponen que el magmatismo a lo largo del pacífico mexicano exhibe un historial episódico caracterizado por distintos pulsos de magmatismo intenso que se ve reflejado en rocas tanto intrusivas como volcánicas. Keppie y Morán-Zenteno (2005) se basaron en la ausencia de "puntos de penetración" (piercing points) comunes en México y Centro América, así como el polo de rotación de la placa Caribe para sugerir una acreción del bloque Chortis por subducción por erosión de la margen pacífica mexicana desde el Eoceno.

Independientemente de la diversidad de interpretaciones del significado tectónico que se le atribuye, la zona de falla Chacalapa registra una actividad documentada que abarca desde el Oligoceno hasta el presente. Exhibe un conjunto de estructuras diacrónicas que reflejan profundidades mesocorticales hasta superficiales que proveen un ejemplo claro de flujo y deformación en una zona de falla.

\section{Agradecimientos}

Gracias a Luigi Solari y a Ángel Nieto Samaniego por la revisión del artículo y sus comentarios. Gabriela Solís hizo una revisión adicional que mejoró el texto. Este trabajo fue financiado parcialmente con el proyecto PAPIIT-UNAM IN102602.

\section{Referencias bibliográficas}

Carfantan, J. C., 1983, Les ensembles geologiques du Mexique meridional. Evolution geodynamique durant le Mesozoique et le Cenozoique: Geofísica Internacional, 22, 9-37.

Carfantan, J. C., 1986, Du systeme Cordillerain Nord-Americain au domain Caraibe: Savoie, Francia, Universite de Savoie, Tesis doctoral, $298 \mathrm{p}$.

Corona-Chávez, P., 1997, Defomazione, metamorfismo e meccanismi di segregazione migmatitica nel Complesso Plutonico-Metamorfico del terreno Xolapa, Messico: Milán, Italia, Universitá Degli Studi di Milano, Tesis doctoral, $78 \mathrm{p}$.

De Cserna, Z., 1965, Reconocimiento geológico en la Sierra Madre del Sur de México, entre Chilpancingo y Acapulco, Estado de Guerrero: Universidad Nacional Autónoma de México, Instituto de Geología, Boletín, 62, $77 \mathrm{p}$.

Delgado-Argote, L., Carballido-Sánchez, E., 1990, Análisis tectónico del sistema transpresivo neogénico entre Macuspana, Tabasco, y Puerto Angel, Oaxaca: Universidad Nacional Autónoma de México, Instituto de Geología, Revista, 9, 21-32.

Ducea, M. N., Gehrels, G. E., Shoemaker, S., Ruiz, J. Valencia, V.A., 2004, Geological evolution of the Xolapa Complex, Southern Mexico. Evidence from U-Pb zircon geochronology: Geological Society of America Bulletin, 116(7/8), 1016-1025.

Ducea, M. N., Valencia,V. A., Shoemaker, S., Reiners, P. W., DeCelles, P. G., Campa, M. F., Moran-Zenteno, D., Ruiz, J. 2005, Rates of sediment recycling beneath the Acapulco Trench: Constraints from (U-Th)/He thermochronology: Journal of Geophysical Research, $109,5,665-5,672$.

Fossen, H., Tikoff, B., 1993, The deformation matrix for simultaneous simple shearing, pure shearing and volume change, and its applications to transpression-transtension tectonics: Journal of Structural Geology, 15, 413-422. 
Guerrero-García, J. C., Silver, L. T., Anderson, T. H., 1978, Estudios geocronológicos en el complejo Xolapa: Boletín de la Sociedad Geológica Mexicana, 39, 22-23.

Hernández-Bernal, M. S., 1995, Geoquímica y origen del Batolito de Río Verde, Oaxaca, Terreno Xolapa: México, D. F., Colegio de Ciencias y Humanidades, Universidad Nacional Autónoma de México, Tesis de maestría, $83 \mathrm{p}$.

Hernández-Bernal, M. S., Morán-Zenteno, D. J. 1996, Origin of the Rio Verde Batholith, southern Mexico, as inferred from its geochemical characteristics: International Geology Review, 38, 361-373.

Herrmann, U. R., Nelson, B. K., Ratschbacher, L., 1994, The origin of a terrane: $\mathrm{U} / \mathrm{Pb}$ zircon geochronology and tectonic evolution of the Xolapa complex (southern Mexico): Tectonics, 13(2), 455-474.

Herz, N., 1978, Titanium deposits in anorthosite massifs: United States Geological Survey, Professional Paper, 959-D, D1-D6.

Hirth, G. Tullis, J., 1992, Dislocation creep regimes in quartz aggregates: Journal of Structural Geology, 14, 145-181.

Keppie, J. D., Morán-Zenteno, D. J., 2005, Tectonic implications of alternative Cenozoic reconstructions for southern Mexico and the Chortis block: International Geology Review, 47, 473-491.

Lazos-Ramírez, Z. G., Rodríguez-Rivera, R. D., 1995. Estudio petrológico y estructural de las rocas cristalinas del área Pochutla-Santo Domingo, Oaxaca: México, D.F., Facultad de Ingeniería, Universidad Nacional Autónoma de México, Tesis de licenciatura, 90 p.

Lister, G. S., Dornsiepen, U. F., 1982, Fabric transitions in the Saxony granulite terrain: Journal of Structural Geology, 4, 81-92.

Meschede, M., 1994, Tectonic evolution of the northwestern margin of the Caribbean plate in the light of the 'Terrane Concept': Structural and geochemical studies in southern Mexico and Costa Rica. Tübingen Geowissenschaftliche Arbeiten, A 22, 113 p.

Morán-Zenteno, D. J., 1992, Investigaciones isotópicas de Rb-Sr y Sm-Nd en rocas cristalinas de la región de Tierra Colorada-Acapulco-Cruz Grande, Estado de Guerrero: México, D.F., Universidad Nacional Autónoma de México, Colegio de Ciencias y Humanidades, Tesis doctoral, $186 \mathrm{p}$

Morán-Zenteno, D., Corona-Chávez, P., Tolson, G., 1996, Uplift and subduction erosion in southwestern Mexico since the Oligocene: Pluton geobarometry constraints: Earth and Planetary Science Letters, 141(1-4), 51-66.

Morán-Zenteno, D. J., Martiny, B., Tolson, G., Solís-Pichardo, G., AlbaAldave, L., Hernández-Bernal, M. S., Macías-Romo, C., MartínezSerrano, R. G., Schaaf, P., Silva Romo, G., 2000, Geocronología y características geoquímicas de las rocas magmáticas terciarias de la Sierra Madre del Sur, en Alaniz-Álvarez, S. A., Ferrari, L., (eds.), Avances de la geología mexicana en la última década: Boletín de la Sociedad Geológica Mexicana, 53, 27-58.

Ortega-Gutiérrez, F., 1981, Metamorphic belts of southern Mexico and their tectonic significance: Geofísica Internacional, 20(3), 177-202.

Ortega-Gutiérrez, F., Corona-Esquivel, R., 1986, La falla de Chacalapa: Sutura críptica entre los terrenos Zapoteco y Chatino (resumen), en Reunión Anual 1986 de la Unión Geofísica Mexicana, GEOS, núm. extraordinario.

Ortega-Gutiérrez, F., Mitre, L. M., Roldán-Quintana, J., Sánchez-Rubio, G., De la Fuente, M., 1990: Ocean-continent transect H-3, Geological Society of America.

Passchier, C. W., Trouw, R. A. J., 1996, Microtectonics, Springer, Heidelberg, $289 \mathrm{p}$.
Paulson, E. G., 1969, Mineralogy and origin of the titaniferous deposit at Pluma Hidalgo, Oaxaca, Mexico: Economic Geology, 59, 753767.

Petróleos Mexicanos (PEMEX), 1986, Informe Final del Proyecto Mixtepec. 52 p. (inédito).

Riller, U., Ratschbacher, L., Frisch, W., 1992, Left-lateral transtension along the Tierra Colorada deformation zone, northern margin of the Xolapa magmatic arc of southern Mexico: Journal of South American Earth Sciences, 5, 237-249.

Robinson, K. L., Gastil, R. G., Campa, M. F., 1989, Early Tertiary extension in southwestern Mexico and exhumation of the Xolapa metamorphic core complex: Geological Society of America Abstracts with Programs.

Sánchez-Rubio, G., 1975, Las migmatitas de PuertoEscondido, Oaxaca: México, D.F., Facultad de Ingeniería, Universidad Nacional Autónoma de México, Tesis de licenciatura, $47 \mathrm{p}$.

Sánchez-Zavala, J. L., 2005, Estratigrafía, sedimentología y análisis de procedencia de la Formación Tecomate y su papel en la evolución del Complejo Acatlán, sur de México: México, D.F., Posgrado en Ciencias de la Tierra, Universidad Nacional Autónoma de México, Tesis doctoral, $226 \mathrm{p}$.

Schaaf, P., Morán-Zenteno, D. J., Hernández-Bernal, M. S., Solís-Pichardo, G., Tolson, G., Köhler, H., 1995, Paleogene continental margin truncation in southwestern Mexico: geochronological evidence: Tectonics, 14, 1339-1350.

Simpson, C., DePaor, D., 1991, The kinematics of high strain zones: Geological Society of America, Annual Meeting (apuntes de curso teórico-práctico).

Tolson, G., Solís-Pichardo, G. N., Morán-Zenteno, D., Victoria-Morales, A., Hernández-Treviño, J. T., 1993, Naturaleza petrográfica y estructural de las rocas cristalinas en la zona de contacto entre los terrenos Xolapa y Oaxaca, región de Santa María Huatulco, Oaxaca, en Delgado Argote, L.A., Martín Barajas, A. (eds.), Contribuciones a la Tectónica del Occidente de México: Unión Geofísica Mexicana, Monografía 1, 327-349.

Tolson, G., 1996, Using a weighted density function to fit an ellipse to the Fry plot. (resumen), en Geological Society of America Abstracts with programs, A71.

Tolson, G. 1998, Deformación, exhumación y neotectónica de la margen continental de Oaxaca: Datos Estructurales, Petrológicos y Geotermobarométricos: México, D. F., Colegio de Ciencias y Humanidades, Universidad Nacional Autónoma de México, Tesis doctoral, $96 \mathrm{p}$.

Tullis, J., 1977, Preferred orientation of quartz produced by slip during plane strain: Tectonophysics, 39, 87-102.

Turner, F. J., Weiss, L. E., 1963, The structural analysis of metamorphic tectonites: New York, Wiley, 563 p.

Weger, M., 1996, Duktile Kinematik kontinentaler Kruste am Beispiel del Zentralgneise de westlichen Tauernfensters (Ostalpen, Österreich und Italien) Strainmethodik, Strainverteilung und Geodynamik. Ludwig-Maximilians Universität: Munich, Tesis doctoral, 186 p.

Manuscrito recibido: Noviembre 14, 2004

Manuscrito corregido recibido: Junio 10, 2005

Manuscrito aceptado: Junio 13, 2005 